\section{Parliament in Brituin}

\section{CEGB Generating Capacity}

ThE Central Electricity Generating Board estimates that this year it will spend about $£ 850,000$ on research connected with $500 \mathrm{MW}$ generating units, and about $£ 1$ million next year. The work will be concentrated primarily on turbines, alternators, lubrication and bearings. This information was given by Dr Ernest A. Davies, joint Parliamentary Secretary to the Ministry of Technology.

Earlier, a number of questions about the CEGB's lack of spare capacity in the event of severe demand were addressed to the Minister of Technology. Mr Wedgwood Benn stated that apart from voltage reductions amounting to between 3 and 6 per cent for eleven days in November, the board has been able to meet demand. He said that faults in the $500 \mathrm{MW}$ generator sets were responsible for the lack of spare capacity, but he gave no undertaking that the board would be able to meet demand during another cold spell, or when the sets would be back in service. Sir John Eden suggested that perhaps the CEGB should have decided on a more flexible plant mix, and Mr Eric Lubbock suggested that at least some of the criticism should be directed at private industry which supplied the faulty equipment. Mr Benn would not comment on the technical aspects of the failures, however, and he did not want to emphasize the part played by private industry because of the effect such a criticism may have on British exports. (Oral answers, January 26.)

\section{Teacher Training Grants}

MR TAM DALYELL asked the Secretary of State for Education and Science what consideration he is giving to the recommendation of the report of the working party of the Royal Society that graduates taking teacher training courses should receive postgraduate grants. Mr Gerald Fowler said, however, that grant arrangements for graduates training as teachers apply to graduates training for a number of other professions, and that he could not consider implementing the working party's recommendation without taking into account many other deserving claims on the funds available for student support. (Written answers, January 29.)

\section{Experiments on Animals}

LORD SILKIN called on the Government to introduce legislation to implement the Littlewood Report on experiments on animals, and to control the export of animals for research. No legislation has been made on this subject since 1876, he said, and the Littlewood Report was completed five years ago. Lord Platt said that although he does not like experiments on live animals, they are necessary for medical research, and that people who call for a complete end to animal experiments should refuse to take antibiotics, insulin, hormones and treatment of that kind. Replying to the debate, Baroness Llewelyn-Davies of Hastoe said that, by law, drugs must be tested on animals before they are marketed, and that if international exchange in special animal strains were restricted, the chances of another disaster on the scale of the thalidomide tragedy could occur. The welfare of animals is safeguarded under the act of 1876, she said, and the government sees no reason for giving new legislation a high priority. (Debate, Lords, January 27.)

\section{Miscellaneous Infelligence}

Rumours that the Committee on Safety of Drugs is to recommend the withdrawal of king size cigarettes must be firmly stubbed out. The committee considers that cigarettes do not fall within its purlieu because they are not therapeutic agents and, unlike contraceptive pills, they are not "a drug administered for the modification of a physiological function". Those naive enough to think the committee is shirking its responsibilities should realize that more fundamental differences underlie this useful distinction between cigarettes and the pill. To start with, the Exchequer's revenue from cigarette duty this year was $£ 980$ million, whereas the pill is not taxed. Moreover, the pill undermines the social fabric by encouraging the sexual independence of women whereas tobacco is a social stimulant hallowed by tradition. It is true that $\mathbf{2 5 , 9 5 2}$ people in Britain died of lung cancer in 1968 , compared with possibly 50 or so from thromboembolism associated with the pill, but that is no concern of the committee because nicotine is not a drug, or if it is, it is not administered to modify a physiological function, and if smokers think otherwise they must be deluding themselves.

THE discrepant estimates of the world's wild tiger population that were provoked by the recent arrival in London of Miss Gina Lollobrigida and her tiger skin maxi-coat (Nature, 225, 215; 1970)-the World Wildlife Fund claimed 600 tigers and the Fauna Preservation Society 2,500-are believed to owe their difference to the old safari saying that for every tiger you see, five tigers see you.

The United States is well on the way to becoming a Grove of Academe. In 1969, 61.4 million people, about 31 per cent of the population, were either teachers or students. Needless to say, production on this scale leads to an occasional glut; at the annual meeting of the American Physical Society in Chicago last month, only 100 employers arrived to interview some 1,500 applicants with doctoral degrees in physics.

A cow is a cow is a one-bar fire and a desalination machine; according to a handout from the Ministry of Agriculture, twenty cows give off the equivalent of 20 kilowatts of heat an hour, which equals the output of 20 one-bar electric fires. In the same interval the twenty bovids perspire 10 pints of moisture between them. Why the ministry does its sums in scores of cows instead of units is not clear unless it hopes thereby to woo farmers gently to decimalization.

\section{How Hoyle found}

IT WILL surprise no one who knows him if this year's top? of the pops turns out to have been written by the director of the Institu

Fred Hoy.'s imagination spends most of its timic on guasi . stelt love objects on the rim of our unit objects on the nim of our uni.
verse which are burning away at a rate which makes the $\mathrm{H}$ bomb look like a bedroom candie. It's naturil territory for a man widely held 10 be But now Hoyle is about 10 sliow
another facet of his dianiond-cut
talent.

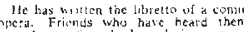

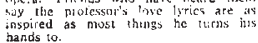
beyond the
Milky Way

From an article in the Daily Mail (February 2) describing how Professor Hoyle has written the libretto to The Alchemy of Love, an opera that will be performed by the Manhattan School of Music in New York next month. 